\title{
Control of an Autonomous Hybrid Microgrid as Energy Source for a Small Rural Village
}

\author{
Américo Joaquim Lampião*, Tomonobu Senjyu*, and Atsushi Yona* \\ "Faculty of Engineering, Department of Electrical and Electronics Engineering \\ *University of the Ryukyus, 1 Senbaru, Nishihara-cho, Nakagami, Okinawa, 903-0213, Japan
}

\begin{abstract}
Article Info
Article history:

Received Oct 7, 2016

Revised Dec 11, 2016

Accepted Dec 24, 2016

\section{Keyword:}

Microgrid

Utility grid

Photovoltaic system

Battery energy system

Power balance

ABSTRACT

Nowadays, the exhaustion of electricity power in rural areas is becoming an important issue for many African Nations. Moreover, challenges include the high cost of extending the power grid to these locations, the economic health of the utilities and lack of revenue in impoverished villages. Numerous new initiatives are being implemented in the countries some of them co-financed by international organizations. In this paper, the hybrid microgrid is carried out as a feasible solution for a small rural village. A model of hybrid microgrid consisting of combination of photovoltaic (PV) panels and battery energy storage (BES) and a control system for managing the components of entire system to feed the village as local load is proposed. The control system must avoid the interruptions of power delivered to the consumers (village) and, therefore, good quality and reliability of the system is required. The PI controllers are used to regulate the voltage and current using three-phase $d q$ transformation, while the parameters are determined using Ziegler-Nichols tuning method. The effectiveness of the proposed method is verified by simulation results given by Matlab/SimPowerSystems ${ }^{\circledR}$ environment.
\end{abstract}

Copyright (C) 2017 Institute of Advanced Engineering and Science. All rights reserved.

\section{INTRODUCTION}

Over 620 million people in Africa still do not have access to the electricity [1]. As known, electricity is an essential contributor to the well-being of people and a key point of economic betterment for any country in the world. In 2001, the US National Academy of Engineers (NAE) voted "electrification" as the most significant engineering achievement of the past century. According the worldwide calculation of electric consumption at present, approximately 1.4 billion people more than 20 percent population all over the world does not have access to electric connection and mostly live in rural areas in Africa [2]. The biggest challenges surrounding energy in this locations is the high cost to extend the power grid from main to these locations. New initiatives are being implemented using renewable energy source, but improvements are still required [3]. In this paper, a model of autonomous hybrid microgrid supplying a small rural village as local load and the respective controller is proposed to demonstrate their feasibility solution in rural villages. The hybrid source is a combined PV panels and Battery storage, connected to the load through voltage source inverter (VSI), filter and isolating transformer. The loads are typically rural such as mills, water pumps for irrigation, and small houses with one or two compartments. The households mainly use the firewood for cooking, therefore, small power for each house is expected. The use of PV panels as renewable energy has advantages due the environmental regulation protection, but the generated power changes according the temperature and solar radiation [4]-[6]. This fact 
generates stability, reliability and power quality problems at the consumers [7]-[11].

The battery is used to overcome the intermittent and uncertain of the photovoltaic (PV) generation [13]. The PV system is composed by PV panels and DC/DC boost converter. In order to maximize the efficiency of the PVs and maintain the voltage at the DC-link, a combination of MPPT (maximum power point tracking) and DC/DC boost converter is used. The MPPT uses an algorithm to maintain the generated power at maximum point [11-13].

Depending on the PV generation and load demand, the battery may operate at either charging or discharging mode. In discharging mode, the battery works as power source and injects power to the inverter and, therefore makes balance between generation and load power demand. In charge mode, the battery receives the power from PV system. These achievements are possible by using a DC/DC bidirectional converter. The VSI is used to interface the DC-side with AC-side and, therefore, to convert DC current to AC with appropriate natural frequency. The inverter operates in high frequency (around 5-20 kHz), and causes harmonic distortions in output current [17]-[21], therefore, in this study a filter harmonics will be taken into account. In this paper, an isolating transformer rated at $100 \mathrm{kVA}$, to step-up the line voltage from $230 \mathrm{~V}$ to $380 \mathrm{~V}$, is used. In addition, power supply companies demand this for the elimination of possible zero sequence or DC components in the generated voltages and for increased protection it affords [9]. This fact can be used as an advantage since the transformer can form part of a filter impedance and may, therefore, reduce the undesired harmonic content of the output current. Power quality standards for connection of an inverter to the load are still under development, since previously there have been few similar high power electronic applications. In this study the important aspect of power quality is harmonic distortion. General requirements for harmonic distortion can be found in standards IEEE [1547.1-1547.8].

The control solution proposed, provides high quality of current delivered to the consumers and, therefore, high power quality. In addition, active and reactive power control is provided. The choice of control variables are based on standards, regulations and procedures presented in scientific publications. PLL (phase locked loop) and PI controllers was used to accomplish the power management of the system using $d q$ synchronous reference. The parameters was determined using Ziegler-Nichols tuning method. Over the years, considerable research has been conducted on current and voltage regulation in microgrids, and various approaches have been proposed. In this paper a review of the latest journal and conference papers related to the control in microgrids are carried out to demonstrate the validity of the proposed method, performed using MATLAB/ SimPowerSystems ${ }^{\circledR}$. Simulation results demonstrate the effectiveness of proposed controller and, therefore, can be used to analyse microgrids connections.

The rest of the section in this paper is organized as follows: In Section II, the proposed model is presented and the main components including control methodology are described. In Section III the discussion of the simulation results to show the effectiveness of the proposed system is presented. Finally, conclusions are drawn in Section IV.

\section{RESEARCH METHOD}

The methodology adopted in this study, is proposing the schematic configuration of the model to be implemented and simulated using Matlab/Simulink environment. The components are described and the simulation results are presented. The conclusion is based on the presented results. Figure 1, shows the proposed model, and the description are presented below.

\subsection{PV System}

The PV array used in this paper acts as an input source for charging the battery as well as supplying to the AC load during normal conditions. The basic equation of a PV panel is presented in [12]. Table 2, shows the constant values for the standard state of each PV panel as used in the present study. As mentioned in preview chapters, the PV generates intermittent power due the variation of sun's radiation and cell temperature. In order to maximize the power and maintain the voltage in DC-link at required level (400 V), a combined MPPT and DC/DC boost converter are used. The MPPT aims at using an algorithm to ensure the array to operate at the maximum power point [6]. There are many different MPPT methods. Perturbation and Observation (P\&O) method is used most widely since it is much simpler and needs fewer measured variables as input. In this study $\mathrm{P} \& \mathrm{O}$ was used and performed according [4]. 


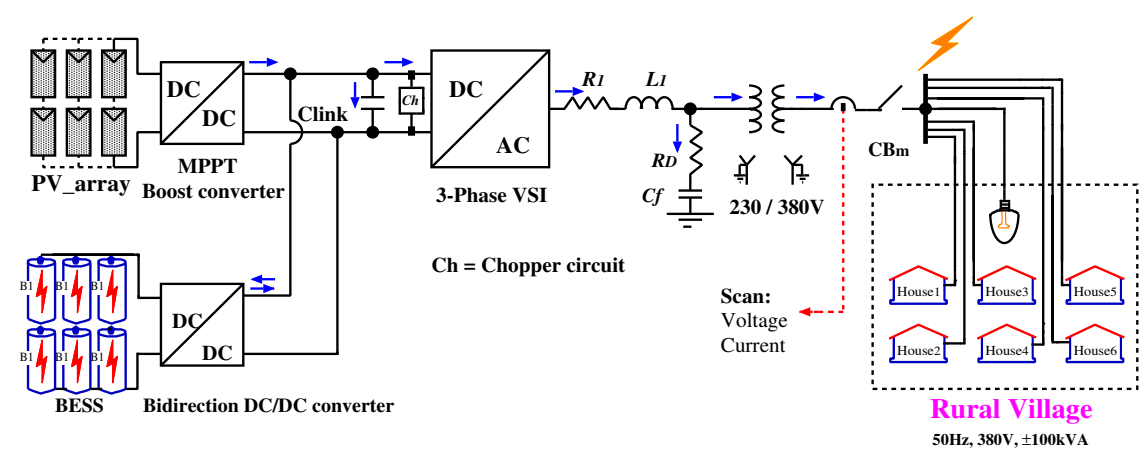

Fig. 1. Proposed system topology.

\subsection{Battery Energy Storage System (BESS)}

The battery is required to improve the system performance of microgrid and make the balance between the generated power and load power demand through charge/discharge energy to or from this storage [8]. In this paper, the battery model is Lithium-Ion taken from the MATLAB/Simulink tools with a nominal voltage of $310 \mathrm{~V}$. The initial state of charge (SOC) of the model can be set according to the need of the simulation. The simulation parameters are shown in Table 1. The battery is connected at the DC-link through a DC/DC bidirectional converter. The objective of this converter is to maintain the voltage on DC-link (400 V) and to operate the system in order to charge/discharge the battery according the different situations. In charge mode the PV generates more than required power and, therefore, the extra power must stored in the battery. In discharge mode, the PV generates less than required power, then the battery injects power to balance the generated power with load power demand. Figure 2, shows the schematic configuration of bidirectional converter and the parameters are achieved according [11], and [15].

Table 1. Parameters of the Battery model.

\begin{tabular}{lc}
\hline \hline Parameter & Value \\
\hline Nominal Voltage [V] & 310 \\
Rated Capacity [Ah] & 8.2 \\
Fully Charged Voltage [V] & 360.836 \\
Nominal current [A] & 7.4157 \\
Initial State-of-Charge [\%] & 80 \\
\hline \hline
\end{tabular}

\subsection{DC-bus dynamics and protection}

A chopper circuit is used in DC-link to dissipate excess power during fault condition or over voltage. If the DC-link voltage exceeds the maximum limit $(425 \mathrm{~V})$, the DC-link will be short-circuited through the resistor $\mathrm{r}_{c}$ and the excess of power will be dissipated in this resistor, then the DC-link voltage will be maintained. A common capacitor $\mathrm{C}_{\text {link }}$ is installed in parallel with chopper circuit as shown in Figure 2. In this study, the value of $r_{c}$ is $300 \Omega$.

\subsection{Inverter characteristics}

The role of power electronics converter is very important in renewable energy systems [11]. In this study, the inverter is set-up in accordance with the circuit shown in Figure 2. An IGBT six pack is modelled and controlled in order to achieve the required objectives. The space-vector (SV) power width modulation (PWM) technique is used to produce the switching control signals to be applied at three-phase inverter. 


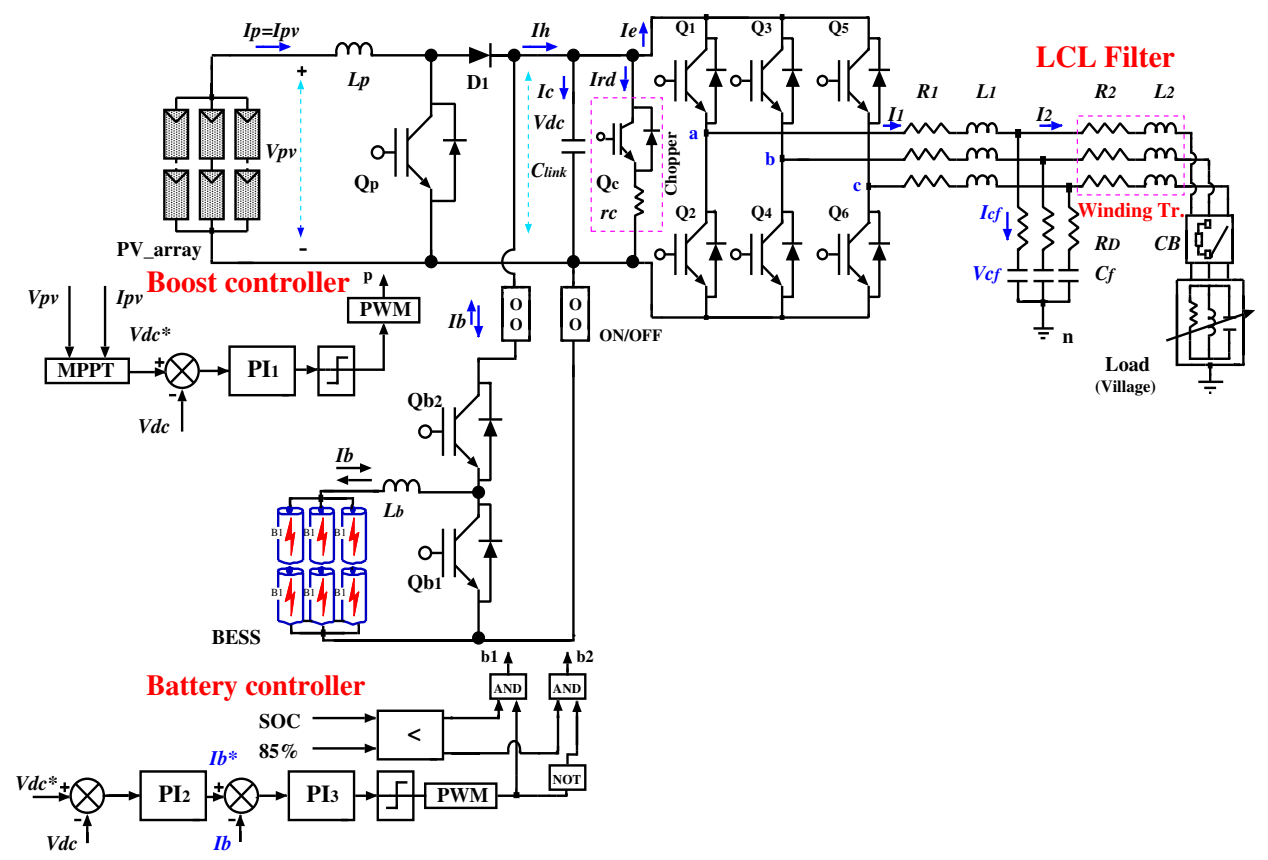

Fig. 2. Detailed system configuration.

\subsection{Harmonics filter and isolating transformer}

In this study, a LC filter combined with equivalent impedance of isolating transformer is used to reduce the harmonics distortions in output inverter. The final configuration is a LCL filter which the components are determined based on [17]. The primary objective of isolating transformer is to step-up the line voltage from $230 \mathrm{~V}$ to $380 \mathrm{~V}$ (nominal load voltage). The parameters are presented in Table 3.

\subsection{Load characteristics}

The main use of electricity is expected to be for lights, mills, bars, water pump for irrigation, and office in village center. The load varies according the season and time. For example, during the rain season the use of water pumps are not required for irrigation, and therefore the load power is small. In this study, the estimated maximum load power is assumed $100 \mathrm{kVA}$ and the line voltage and natural frequency is $380 \mathrm{~V}$ and $50 \mathrm{~Hz}$, respectively.

Table 2. PV panel constants.

\begin{tabular}{llc|lcc}
\hline \hline Parameters & Value & Parameters & Value \\
\hline Short-circuit current & $I_{s c}$ & $8.36 \mathrm{~A}$ & Number of cells per module $N_{c e l l s}$ & 54 \\
Open circuit voltage & $V_{o c}$ & $33.20 \mathrm{~V}$ & Number of panels in series $N_{s}$ & 14 \\
Voltage at maximum power point & $V_{m p p}$ & $26.3 \mathrm{~V}$ & Number of panels in parallel $N_{p}$ & 80 \\
Current at maximum power point & $I_{m p p}$ & $7.61 \mathrm{~A}$ & Diode quality factor $A$ & 1.5 \\
Temperature coefficient of $I_{s c}$ & 0.00502 & Series resistance $R_{s}$ & $0.16 \Omega$ \\
Elementary charge $q$ & $1.6 \times 10^{-19} C$ & Parallel resistance $R_{p}$ & $1010.60 \Omega$ \\
Boltzmanns constant $B$ & $1.38 \times 10^{-23}$ & Energy gap $E_{g}$ & $1.2 \mathrm{~V}$ \\
\hline \hline
\end{tabular}

\section{CONTROL OF THE SYSTEM}

The overall control structure consists of a DC-link voltage controller and a line current controller. To supply a line current with low distortion, the connection to the grid is made by an AC filter [17] which consists of combination of LC and equivalent impedance of isolating transformer used to boost the line voltage from 
$230 \mathrm{~V}$ to $380 \mathrm{~V}$. The final configuration is LCL filter, as shown in Figure 2. The control is made in $d q$ reference and PLL is used to regulate the system frequency. In order to achieve good performance of control parameters, the poles and zeros of transfer function was verified.

\subsection{Control of Boost and Bidirectional DC/DC converters}

The linearisation of boost and bidirectional DC/DC converters are analysed and presented in [8] and [15]. From this analysis, the voltage and current transfer functions are given by:

$$
\begin{aligned}
G_{(v)} & =\frac{\widehat{V}_{\text {out }}}{\widehat{d}}=\frac{-\frac{L}{(1-D)^{2}} V_{\text {in }} s+R V_{\text {in }}}{R L C s^{2}+L s+R(1-D)^{2}} \\
G_{(i)} & =\frac{\widehat{I}_{\text {in }}}{\widehat{d}}=\frac{\frac{V_{\text {in }}}{(1-D)}(2+R C s)}{R L C s^{2}+L s+R(1-D)^{2}}
\end{aligned}
$$

where $V_{\text {out }}$ is reference output voltage $(400 \mathrm{~V}), V_{\text {in }}$ is input voltage, $I_{i n}$ is the inductor current, $L$ is inductor, $C$ is common capacitor in DC-link, $D$ is the duty cycle and $R$ is the equivalent load resistor. The details about this task is presented in [11]. In this paper, the equation (1) and (2) was used to design the DC/DC boost controller and DC/DC bidirectional converter. As mentioned in above chapters, Ziegler-Nichols tuning method was used to achieve the control parameters. Figures 4(b) and -(d), show the tuning block diagrams of voltage and current. The inductances of boost and bidirectional converters used in this study are $3 \mathrm{mH}$ and $1 \mathrm{mH}$, respectively.

\subsection{DC-link voltage regulator}

The purpose of the DC-link voltage controller is to preserve the DC-link voltage at its reference value $\left(V d c^{*}\right)$ and to provide the reference power $\left(P_{e}\right)$. To design the DC-link voltage regulator, the following assumptions are considered.

- The grid voltage amplitude is constant;

- Using rotary axes $d q$, the grid voltage $V g$ coincides with $d$-axis;

- The unity power factor is required, then the displacement between the grid voltage and current is zero. Their $q$-axis components are also zeros.

For an accurate control model, it was made a linearisation in DC-side. Figure 2, shows the schematic configuration. In normal condition the gate of IGBT $\left(Q_{c}\right)$ receives the signal zero, meaning that the chopper circuit is opened and no current is flowing through dump-resistor. Neglecting the chopper circuit, the DC side of the inverter can be described as follows:

$$
\left\{\begin{array}{l}
i_{h}=i_{e}+i_{c} \\
i_{e}=\gamma_{a} i_{a}+\gamma_{b} i_{b}+\gamma_{c} i_{c} \\
i_{c}=C_{l i n k} \frac{v_{d c}}{d t} \\
P_{h}=i_{h} v_{d c}
\end{array}\right.
$$

where $i_{c}$ is current through the DC-link capacitor, $P_{h}$ is available hybrid active power at specific solar radiation and SOC, $C_{\text {link }}$ is DC-link capacitor, $i_{h}$ is the hybrid current, $V_{d c}$ is voltage in DC-link, $i_{e}$ is the current delivered to the inverter (which is a function of the line currents $i_{a}, i_{b}, i_{c}$, and the states of the power-poles $\gamma_{a}, \gamma_{b}, \gamma_{c}$ (1: 'on', 0:'off', $\gamma_{i} \backslash+$ upper pole, $\gamma_{i} \backslash$ - lower pole in the 3-phase VSI).

To achieve steady state operation the supplied DC power of the $P h$ and the AC power for load must be balanced. The DC voltage controller gives the set point of the AC power. Assuming, in this paper, that there is no power losses in the inverter, if only active power is to be injected into the grid (load):

$$
\left\{\begin{array}{l}
P_{e} \approx P_{g}=3 \cdot V_{g} \cdot I_{g}=\frac{3}{2} \cdot V_{g} d \cdot I_{g} d \\
Q_{e} \approx 0
\end{array}\right.
$$

The generated hybrid power and the link capacitor power are expressed by equations (3) and (4), respectively:

$$
P_{h y b r i d}=I_{h} \cdot V_{d c}
$$




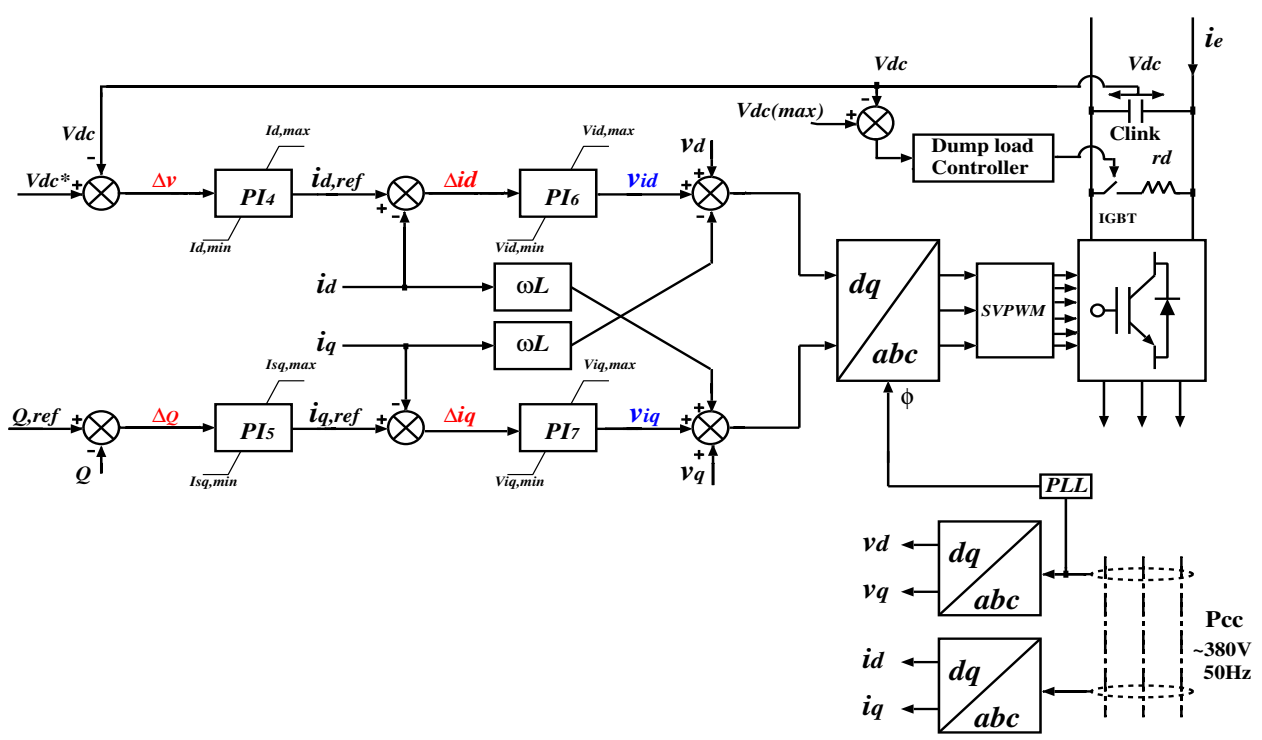

Fig. 3. Control scheme of the grid-side inverter.

$$
P_{\text {capacitor }}=C_{\text {link }} \cdot V_{d c} \cdot \frac{d V_{d c}}{d t}
$$

The VSI losses are neglected, then the following relationship is verified:

$$
P_{\text {grid }}=P_{\text {hybrid }} \cdot P_{\text {capacitor }}
$$

Following equations (3) to (7), the relation between DC-link voltage and the grid current expressed in rotary axis is obtained:

$$
V_{d c}=\frac{1}{C_{l i n k} \cdot s}\left(I_{h}-\frac{3}{2} \frac{V_{g} d}{V_{d c}} \cdot I_{g} d\right)
$$

where $V_{g}$ or $V_{s}$ is the reference phase voltage in output inverter $(132.8 \mathrm{~V})$. The DC-link voltage is regulated imposing a reference in the active current component $\left(I_{g} d\right)$. A voltage variation in the DC-link is compensated by changing the AC line active currents, in such a way that the DC-link is kept at the established value (400 V). The PIs are used as regulators and their parameters are achieved by using Ziegler-Nichols tuning method. The DC-link voltage control loop is presented in Figure 4(b).

\subsection{VSI and Grid current controller}

The output current controller consists of a model based on LCL filter configuration, as shown in Figure 2. According Kirchhoff's rules, we obtain the equations:

$$
\begin{gathered}
\overrightarrow{v_{i}}-\overrightarrow{i_{1}} R_{1}-L_{1} \frac{d \overrightarrow{i_{1}}}{d t}-\overrightarrow{i_{c}} R d-\overrightarrow{v_{c f}}=0 \\
\overrightarrow{v_{s}}+\overrightarrow{i_{2}} R_{2}+L_{2} \frac{d \overrightarrow{i_{2}}}{d t}-\overrightarrow{i_{c}} R d-\overrightarrow{v_{c f}}=0 \\
\overrightarrow{i_{c}}=\overrightarrow{i_{1}}-\overrightarrow{i_{2}}
\end{gathered}
$$

The equivalent equations of (9), (10) and (11) can be described as:

$$
\begin{aligned}
& \frac{d}{d t} \overrightarrow{i_{1}}=-\frac{\left(R_{d}+R_{1}\right)}{\left(L_{1}\right)} \overrightarrow{i_{1}}+\frac{R_{d}}{L_{1}} \overrightarrow{i_{2}}+\frac{1}{L_{1}} \overrightarrow{v_{c f}}+\frac{1}{L_{1}} \overrightarrow{v_{i}} \\
& \frac{d}{d t} \overrightarrow{i_{2}}=-\frac{\left(R_{d}+R_{2}\right)}{\left(L_{2}\right)} \overrightarrow{i_{2}}+\frac{R_{d}}{L_{2}} \overrightarrow{i_{1}}+\frac{1}{L_{2}} \overrightarrow{v_{c f}}-\frac{1}{L_{2}} \overrightarrow{v_{s}}
\end{aligned}
$$




$$
\frac{d}{d t} \overrightarrow{v_{c f}}=\frac{1}{C_{f}}\left(\overrightarrow{i_{1}}-\overrightarrow{i_{2}}\right)
$$

where, $\overrightarrow{i_{1}}=\left[\begin{array}{lll}i_{1_{a}} & i_{1_{b}} & i_{1_{c}}\end{array}\right]^{t}$ is the output current at filter, $\overrightarrow{i_{2}}=\left[\begin{array}{lll}i_{2_{a}} & i_{2_{b}} & i_{2_{c}}\end{array}\right]^{t}$ is the current injected to the grid; $\overrightarrow{v_{c f}}=\left[\begin{array}{lll}v_{c f_{a}} & v_{c f_{b}} & v_{c f_{c}}\end{array}\right]^{t}$ is the voltage in capacitor $C_{f}$.

The control system is made by using voltage and current measurements. In order to reduce the number of measurement sensors, and therefore, minimizing the cost of project, we consider only two sensors to detect voltage and current. The basic control principles used in this paper are generally based on the decoupled current control presented in [17], and [18]. The three-phase voltage on load bus is measured and transformed into a $d q$ reference frame $\left(v_{d}\right.$ and $\left.v_{q}\right)$. The three-phase current flowing between the loads and the inverter is measured and transformed to $i_{d}$ and $i_{q}$. With the comparisons of the $d q$ components to their respective references, the resulting errors are sent to the PI controllers to generate the required output voltage of the inverter.

In order to facilitate the equation analysis, many researches make approximations such that the output current inverter is assumed equal with the output current at the filter $\left(i_{1} \approx \mathbf{i}_{2}\right)$, because the current $i_{c}$ is very small [20]-[21]. Considering this approximations, the filter is analysed as $R L$ and the parameters are the summation of filter impedance and equivalent internal impedance of the transformer $\left(R_{t}=R_{1}+R_{2}\right.$, and $\left.L_{t}=L_{1}+L_{2}\right)$. In this paper, this assumptions are used to achieve the decoupled equations:

$$
\frac{d}{d t} \overrightarrow{i_{1_{d q}}}=\left[\begin{array}{cc}
-\frac{R_{t}}{L_{t}} & \omega \\
-\omega & -\frac{R_{t}}{L_{t}}
\end{array}\right] \overrightarrow{i_{1_{d q}}}-\frac{1}{L_{1}} \overrightarrow{v_{s_{d q}}}+\frac{1}{L_{1}} \overrightarrow{v_{i_{d q}}}
$$

where, $\omega$ is the system frequency in $\mathrm{rad} / \mathrm{s}$. From (15) is obtained:

$$
\begin{aligned}
& V_{i_{d}}=\left(R_{t}+L_{t} s\right) I_{1_{d}}+V_{s_{d}}-\omega L_{t} I_{1_{q}} \\
& V_{i_{q}}=\left(R_{t}+L_{t} s\right) I_{1_{q}}+V_{s_{q}}+\omega L_{t} I_{1_{d}}
\end{aligned}
$$

In equation (16) and (17), considering:

$$
\begin{aligned}
& V_{d}^{\prime \prime}=\left(R_{t}+L_{t} s\right) I_{1_{d}} \\
& V_{q}^{\prime \prime}=\left(R_{t}+L_{t} s\right) I_{1_{q}}
\end{aligned}
$$

The equivalent equation become:

$$
\begin{aligned}
& V_{i_{d}}=V_{d}^{\prime \prime}+V_{s_{d}}-\omega L_{t} I_{1_{q}} \\
& V_{i_{q}}=V_{q}^{\prime \prime}+V_{s_{q}}+\omega L_{t} I_{1_{q}}
\end{aligned}
$$

The plant is a first order system with transfer function

$$
G(s)=\frac{I_{1_{d q}}(s)}{V_{i_{d q}}(s)}=\frac{1}{R_{t}+s L_{t}}
$$

The PI transfer function without derivative action is given by:

$$
T_{s}=K_{p}+\frac{K_{i}}{s}=K_{p}\left(1+\frac{1}{T_{i} s}\right)
$$

Where $T_{i}=\frac{K_{p}}{K_{i}}$ is integral time constant or reset time, $K_{p}$ and $K_{i}$ is proportional and integral gains, respectively. The goal of tuning method is to find the proper gains in order to achieve the required reference values. The block diagrams of control loops are shown in Figure 4(a) and -(c).

\section{RESULT AND ANALYSIS}

In order to demonstrate the effectiveness of the proposed control strategy, a combined PV and BESS (hybrid) connected to the load through three-phase VSI was set up and simulated under three different scenarios using sampling time $20 \mu \mathrm{s}$ and time domain from 0 to $0.55 \mathrm{~s}$. The temperature is assumed constant $25^{\circ} \mathrm{C}$ and sudden changes of solar radiation was implemented as input of PV panels. The initial SOC is $80 \%$ in all scenarios.

a) Case Study 1: This scenario aims to confirm the functionalities of PV and BESS under solar variations to supply the load rated with power $100 \mathrm{~kW}$. The simulation is carried out in sequence as follows: 


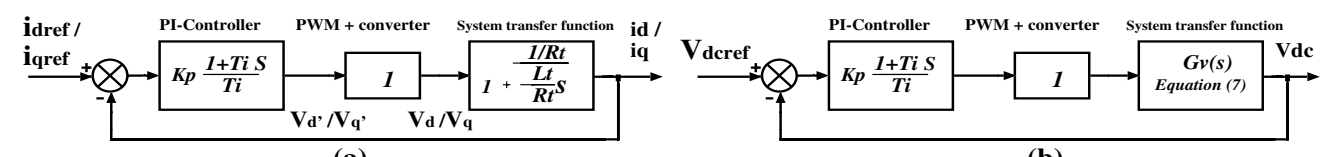

(a)

(b)

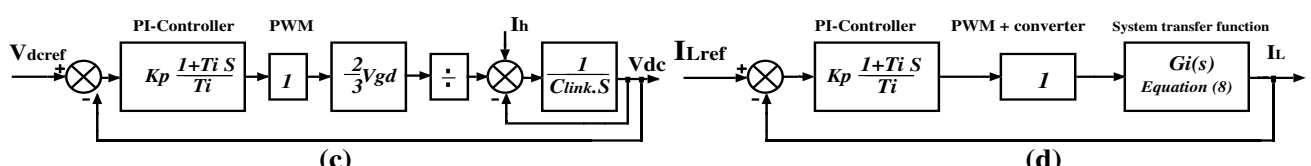

(c)

(d)

Fig. 4. Block diagrams of control loops.

Table 3. Grid parameters and control gains

\begin{tabular}{|c|c|c|c|}
\hline Parameters & Value & Parameters & Value \\
\hline Filter inductance $L_{1}$ & $265 \mu H$ & Switching frequency $f_{s}$ & $20 \mathrm{kHz}$ \\
\hline Filter resistance $R_{1}$ & $40 \mathrm{~m} \Omega$ & Natural frequency $f$ & $50 \mathrm{~Hz}$ \\
\hline Filter resistance $R_{d}$ & $100 \mathrm{~m} \Omega$ & Frequency modulation $P W M$ & $10 \mathrm{kHz}$ \\
\hline Filter capacitor $C_{f}$ & $300 \mu C$ & $\mathrm{PI}_{4}=P I_{5} \quad\left[K_{p}, K_{i}\right]$ & {$[2.1,253]$} \\
\hline Transformer inductance $L_{2}$ & $185 \mu H$ & $\mathrm{PI}_{6}=P I_{7} \quad\left[K_{p}, K_{i}\right]$ & {$[0.004,0.21]$} \\
\hline Transformer resistance $R_{2}$ & $25 \mathrm{~m} \Omega$ & $\left.K_{p}, K_{i}\right]$ & {$[0.0006,0.13]$} \\
\hline Dc-link capacitor $C_{\text {link }}$ & $470 \mu C$ & {$\left[K_{p}, K_{i}\right]$} & {$[0.0002,0.18]$} \\
\hline Peak load power $P_{\text {load }}$ & $100 \mathrm{~kW}$ & {$\left[K_{p}, K_{i}\right]$} & {$[0.0004,0.21]$} \\
\hline
\end{tabular}

At $t=0.0 \mathrm{~s}$, the simulation starts when the solar radiation is maximum $\left(1 \mathrm{~kW} / \mathrm{m}^{2}\right)$, therefore, the PV panels are generating more than required load power. In this case, the excess power is stored in battery. The maximum power injected to the inverter is $115.15 \mathrm{~kW}$, means that $100.0 \mathrm{~kW}$ is for load and $15.15 \mathrm{~kW}$ is total loss in inverter, filter, transformer and lines. In that period the battery is receiving power and therefore, the SOC rises gradually (charging mode). At $t=0.2 \mathrm{~s}$, the solar radiation drops suddenly until $0.5 \mathrm{~kW} / \mathrm{m}^{2}$ and the PV panels start to generate less than required power. In that moment, the battery detects the problem and starts to inject the power to the inverter in order to balance the generation with the load demand. Therefore, the battery starts to discharge and the SOC decreases gradually. At $t=0.4 \mathrm{~s}$, the solar radiation suddenly rises until $\left(1 \mathrm{~kW} / \mathrm{m}^{2}\right)$ and the PV panels starts again to generate more than required power, then the battery changes from discharge to charge mode. During this process, the DC-link voltage, power injected in inverter, voltage, and load current are maintained at $400 \mathrm{~V}, 115.15 \mathrm{~kW}, 380 \mathrm{~V}$ and $300 \mathrm{~A}$, respectively as the graphics shown in Figure 5.

b) Case Study 2: This scenario aims to confirm the functionalities of PV and BESS under load variation and solar radiation at $0.5 \mathrm{~kW} / \mathrm{m}^{2}$. The simulation is carried out in sequence as follows: At $t=0.0 \mathrm{~s}$, the simulation starts when the load is $70.0 \mathrm{~kW}$ solar radiation at $0.5 \mathrm{~kW} / \mathrm{m}^{2}$, therefore, the PV panels are generating more than required load power. In this case, the excess power is stored in battery. The system is injecting in inverter $80.0 \mathrm{~kW}$, meaning that an amount of power is to compensate the losses. In that period the battery is receiving power and therefore, the SOC is increasing gradually. At $t=0.2 \mathrm{~s}$, the load increases until $100 \mathrm{~kW}$, then in that time the load power becomes more than generated power. In order to compensate the generation, the battery starts to inject the power to make balance. While the battery is injecting power, the battery is being discharged and therefore, the SOC is gradually decreasing. At $t=0.4 \mathrm{~s}$, the load power suddenly drops then the battery changes from discharge to charge mode in order to store the excess generated power. Figure 6(a), shows the behaviour of solar radiation, -(b) shows the voltage on DC-link, -(c) shows the battery current, -(d) shows the SOC, -(e) shows the active power injected in inverter, -(e) and -(f) show the voltage and current in load bus.

c) Case Study 3: This scenario aims to confirm the functionalities of PV and BESS under faults, load and solar variations. The simulation is carried out in sequence as follows: At $t=0.0 \mathrm{~s}$, the simulation starts when the all load is connected $100.0 \mathrm{~kW}$ and the solar radiation is maximum. The PV panels are generating more than required power. Therefore the excess power is stored in battery. At $t=0.1 \mathrm{~s}$, an instantaneous fault occur on load bus and transients are observed. When the fault is removed, the system becomes stable. At $t=0.15 \mathrm{~s}$, some loads are disconnected from the grid and, therefore, the power injected in inverter reduces until $70 \mathrm{~kW}$. At $t=0.2 \mathrm{~s}$, a similar fault occur in load bus and the transients are observed again. When the fault is removed the system becomes stable. At $t=0.25 \mathrm{~s}$, all load is connected $(100 \mathrm{~kW})$ and therefore the injected power increases 
too. At $t=0.28 \mathrm{~s}$, the solar radiation drops until $0.5 \mathrm{~kW} / \mathrm{m}^{2}$ and the battery starts to inject power to compensate the generated power according the load demand. At $t=0.38 \mathrm{~s}$ and $0.48 \mathrm{~s}$, instantaneous faults occur on load bus and transients are verified. When the voltage on DC-link exceeds $425 \mathrm{~V}$, the chopper circuit detects and an amount of power is suppressed by dump-load resistor in order to rapidly balance the voltage. Figure 7 , shows the graphics under study. This results demonstrate that the system is controllable and the voltage and current delivered to the consumers have good quality. Figure 7(f), shows the total harmonic distortion (THD=3.94 \%).

\section{CONCLUSION}

This paper has proposed a model of autonomous hybrid microgrid powering through inverter a small rural village and the design of respective controller to regulate the instantaneous output voltage. The graphs obtained during the simulations, explain in detail the system's versatility in different operating condition. The system proves how a renewable source of energy such as PV panels can work together with battery in microgrid to power local loads. Battery storage improves the reliability of the system by overcoming the PV generation in order to balance with the load demand. The battery storage acts as DC load during charge mode, and as DC source during discharge mode. The system was accurately modelled using Matlab/simulink and the parameters have been chosen according the standards and methodologies presented in literatures. The simulation results demonstrate the effectiveness of the proposed model and respective control methodology.

\section{ACKNOWLEDGEMENT}

The authors are really expressing their gratitude to the Senjyu's Lab. members at the Department of Electrical and Electronic Engineering, for their contributions.

\section{REFERENCES}

[1] UN Documents Gathering a body of global agreements, Chapter 7 of the charter of the United Nations Signed in San Francisco, California on June, 1945. http://www.un-documents.net/k-002988.htm.

[2] A. H. Khan, et al., "A Noble Design of a DC Micro Grid for Rural Area in Bangladesh, "International Journal of Technology Enhancements and Emerging Engineering Research, vol. 3, pp. 19-26, 2015.

[3] C. Marnay, et al., "Optimal Technology Selection and Operation of Commercial-Building Microgrids, " IEEE Transactions on Power Systems, vol. 23, no. 3, pp. 975-982, August 2008.

[4] M. G. Villalva, et al., "Comprehensive Approach to Modeling and Simulation of Photovoltaic Arrays, " IEEE Transactions on Power Electronics, vol. 24, no. 5, pp. 1198-1208, May 2009.

[5] S. Rahman and H. A. Rahman, "Use of Photovoltaics in Microgrid as Energy Source and Control Method using MATLAB/Simulink," International Journal of Electrical and Computer Engineering (IJECE), vol. 6, no. 2, pp. 851-858, April 2016.

[6] G. Sekar and T. Anita, "Design and implementation of solar PV for power quality enhancement in Threephase four-wire distribution system, " Journal of Electrical Engineering and Technology (JEET), pp. 75-82, 2015. http://dx.doi.org/10.5370/JEET.2015.10.1.075.

[7] Z. Miao, et al., "An SOC based battery management system for microgrids, " IEEE Transactions on Smart Grid, vol. 5, no. 2, pp. 966-973, 2014.

[8] M. Miyagi, et al., "Uninterruptible smart house equipped with the phase synchronization control system," International Journal of Electrical Power and Energy Systems, Elsevier, vol. 63, pp. 302-310, 2014.

[9] R. Majumder, et al., "Control and protection of a microgrid connected to utility through back-to-back converters, " Electric Power Systems Research, Elsevier, vol. 81, pp. 1424-1435, 2011.

[10] M. Prodanovic, and T. C. Green, "Control and filter design of three-phase inverters for high power quality grid connection," IEEE Transactions on Power Electronics, vol. 18, no. 1, pp. 373-2003, January 2003.

[11] R. Erickson, and D. Maksmovic, "Fundamentals of power electronics, " Kluwer Academic Publishers, vol. 2, pp. 5-350, 2000.

[12] H. Bellia, et al., "A detailed modeling of photovoltaic module using Matlab," NRIAG Journal of Astronomy and Geophysics, vol. 3, pp. 53-61, May 2014.

[13] H. Matayoshi, et al., "Uninterrupted smart house equipped with a single-phase dq-transformation system, " Journal of Renewable and Sustainable Energy, vol. 8, 025101 (106) doi:10.1063/1.4942781. 
[14] A. Panda, et al.,"A single phase photovoltaic inverter control for grid connected system," Sadhana, Indian Academy of Sciences, vol. 41, no. 1, pp. 15-30, January 2010.

[15] M. Gowda, et al., "Moddeling of Buck DC-DC converter using Simulink," International Journal of Innovative Research in Science, Engineering and Technology, vol. 3, pp. 14965-14975, July 2014.

[16] N. Wang, at al., "Battery energy storage system information modeling based on IEC 61850," Journal of Power and Energy Engineering, vol. 2, pp. 233-238, April 2014.

[17] M. Liserre, et al., "Design and Control of an LCL-Filter-Based Three-Phase Active Rectifier, " IEEE Transactions on Industry Applications, vol. 41, no. 5, pp. 1281-1291, 2005.

[18] T. Raju, and P. R. Reddy, "A Novel Control Algorithm for an Adaptive Hysteresis Band Current Controlled Shunt Active Power Filter, " International Refereed Journal of Engineering and Science (IRJES), pp. 10-16, 2014.

[19] S. Bhat, et al., "Effect of Parasitic Elements on the Performance of Buck-Boost Converter for PV Systems," International Journal of Electrical and Computer Engineering (IJECE), vol. 4, no. 6, pp. 831-836, December 2014.

[20] X. Bao, et al., "Feedback Linearization Control of Photovoltaic inverter with LCL Filter, " 2012 IEEE 7th International Power Electronics and Motion Control Conference - ECCE Asia, pp. 2197-2201, June 2012.

[21] M. G. M. Abdolrasol, and S. Mekhilef, "Three phase grid connected anti-islanding controller based on distributed generation interconnection, " 2010 IEEE International Conference on Power and Energy (PECon2010), pp. 717-722, 2010.

\section{BIOGRAPHIES OF AUTHORS}
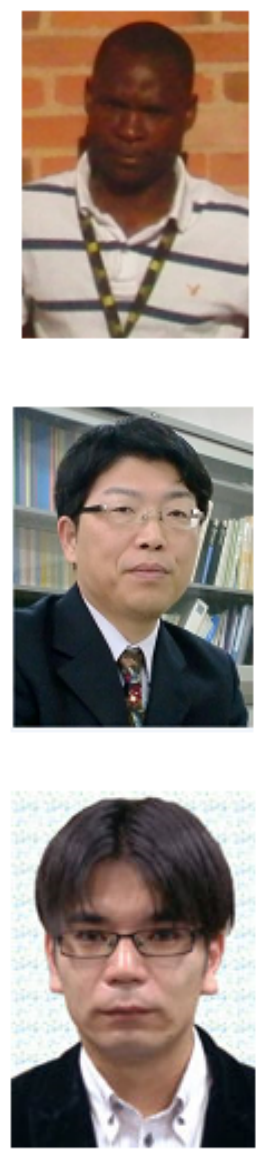

Américo Joaquim Lampião received his B.S. degree in electrical engineering from Universidade Eduardo Mondlane at Mozambique in 2009. Currently, he is pursuing Master degree in electrical engineering at Graduate School of Engineering and Science at University of the Ryukyus, Japan. Besides, he is a junior Engineer at the Electricidade de Moçambique (EDM), the national electricity utility in Mozambique. His researches interests include power electronics, smart grid, microgrids, voltage stability, power protection and electricity markets. He is affiliated with Order of Engineers of Mozambique, and with IEEE as student member.

Tomonobu Senjyu received the B.S. and M.S. degrees in electrical engineering from University of the Ryukyus Japan and the Ph.D. degree in electrical engineering from Nagoya University, Japan. Since 1988, he has been with the Department of Electrical and Electronic Engineering, Faculty of Engineering, University of the Ryukyus, where he is currently working as a Professor. His current research interests include stability of ac machines, advanced control of electrical machines, power electronics, renewable energy and smart grid.

Atsushi Yona received the B.S., M.S. and the Ph.D. degree from the University of the Ryukyus, Okinawa, Japan, in 2006, 2008 and 2010, respectively, all in electrical engineering. In 2008, he joined the University of the Ryukyus, where he is now a Assistant Professor at the Department of Electrical and Electronic Engineering. His research interests include the renewable energy, forecasting techniques and optimal planning. Dr. Yona is a member of the Institution of Electrical Engineers of Japan. 


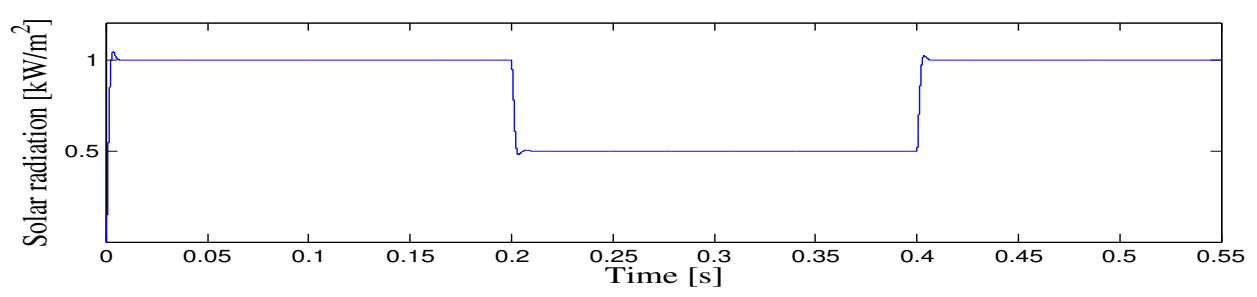

(a) Solar radiation.

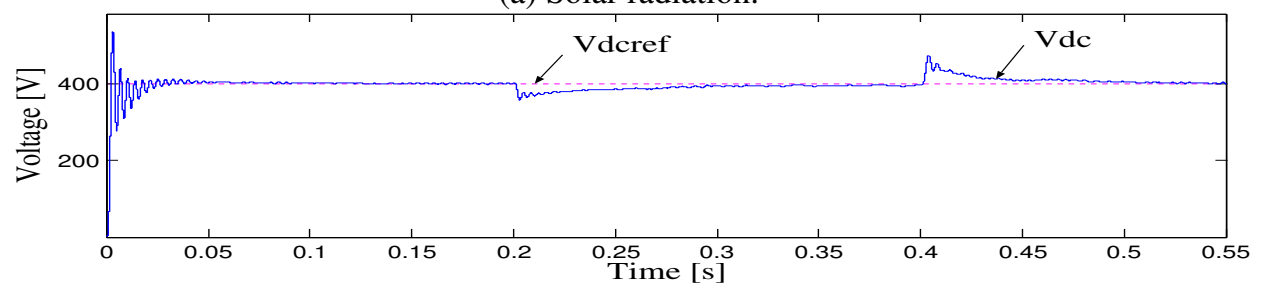

(b) Voltage on Dc-link $(V d c-l i n k)$.

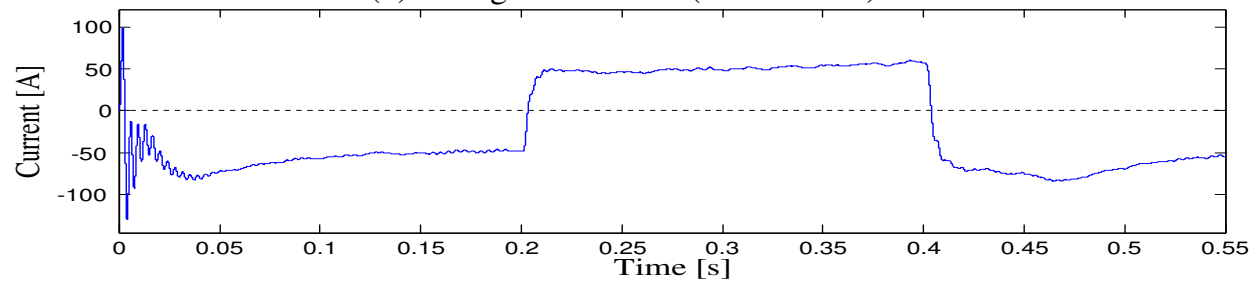

(c) Battery current $(i b)$.

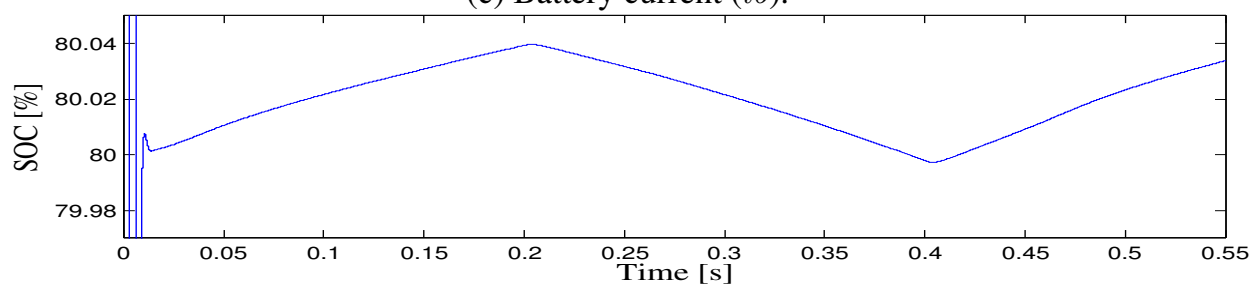

(d) State-of-Charge $(S O C)$.

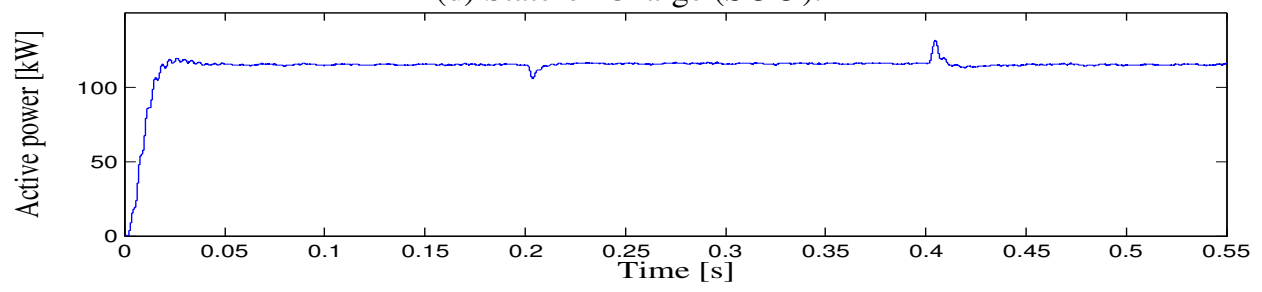

(e) Active power injected into inverter $(\mathrm{Pe})$.

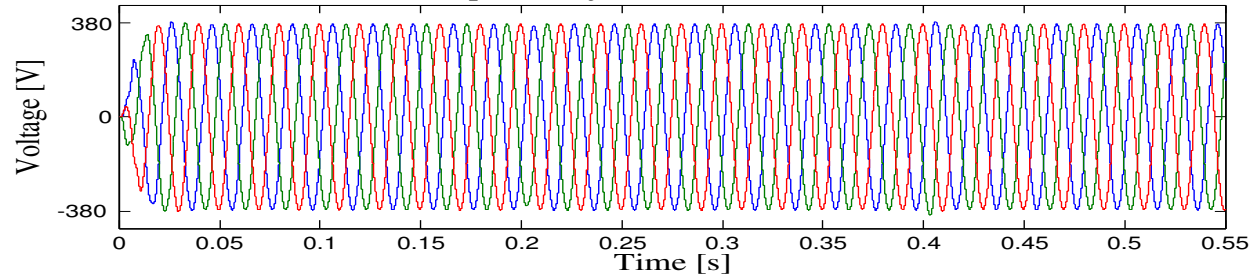

(f) Three-phase load voltage $(V a b c)$.

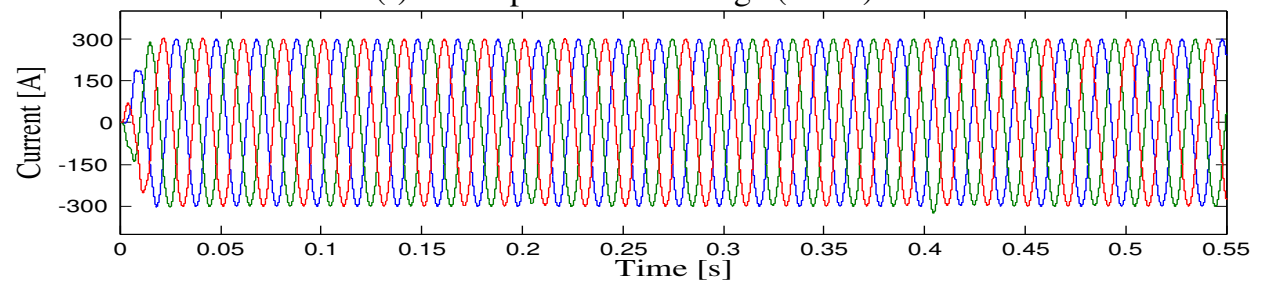

(g) Load current (Iabc).

Fig. 5. Simulation results (Scenario - 1) 


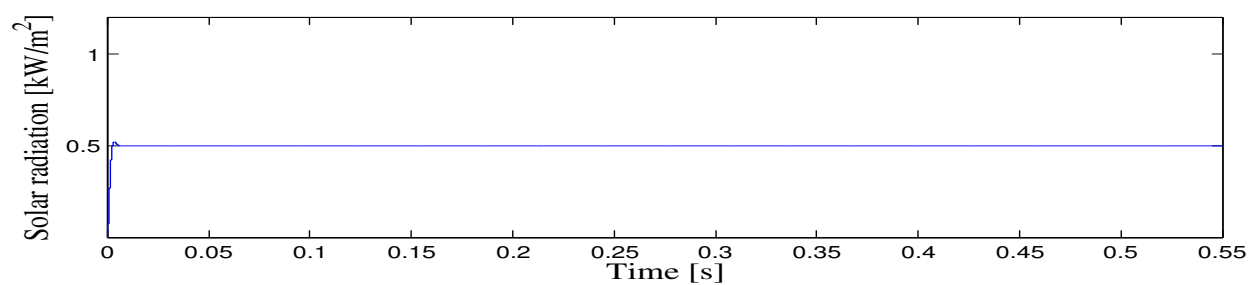

(a) Solar radiation.

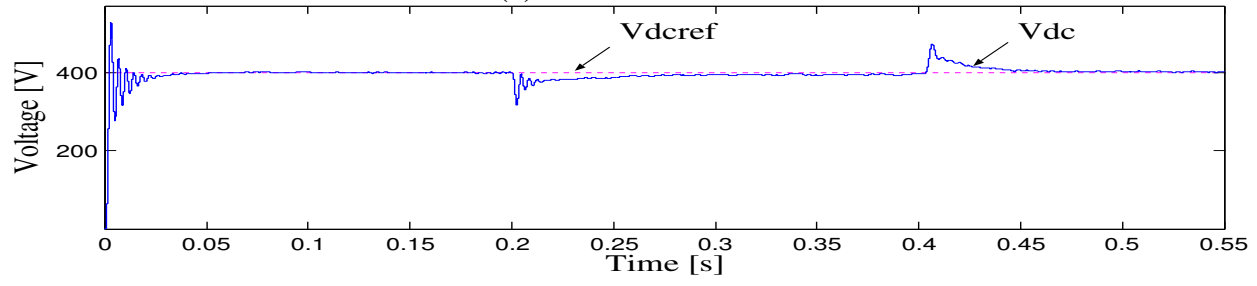

(b) Voltage on Dc-link $(V d c-l i n k)$.

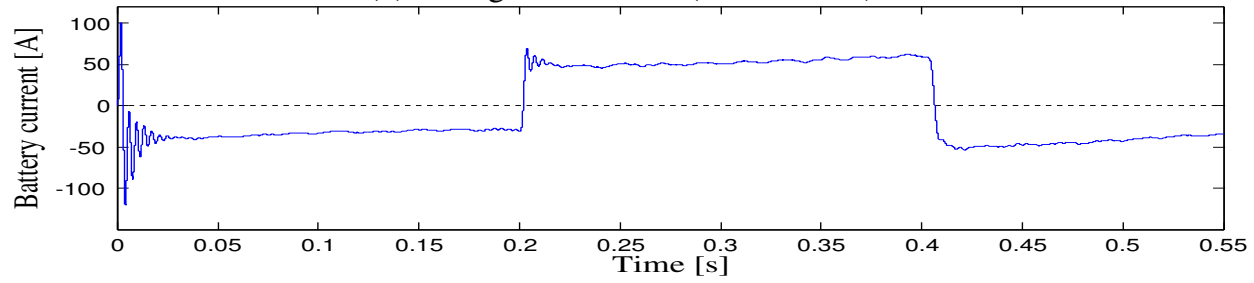

(c) Battery current $(i b)$.

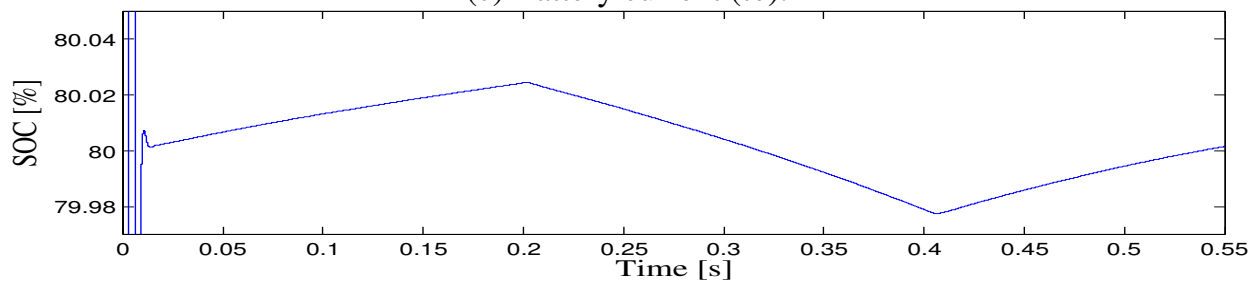

(d) State-of-Charge $(S O C)$.

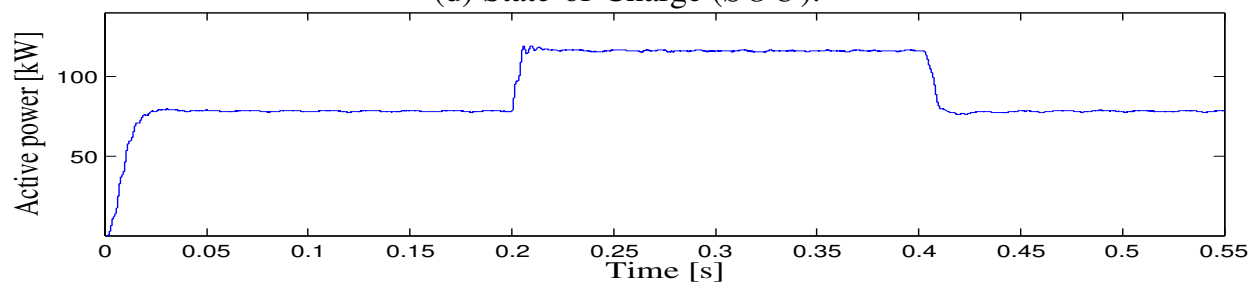

(e) Active power injected into inverter $(\mathrm{Pe})$.

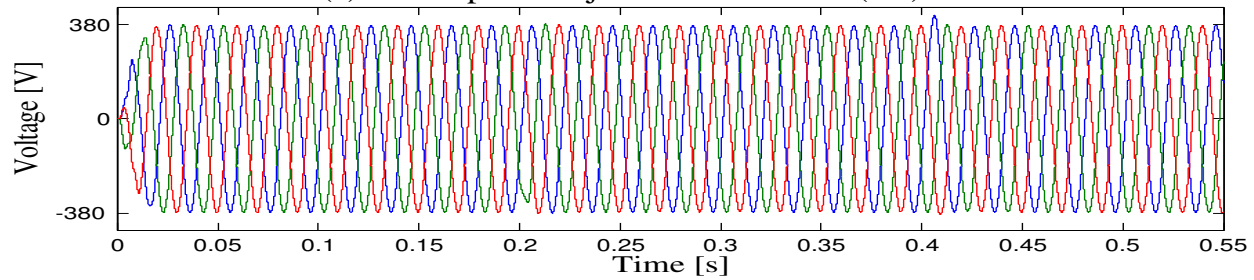

(f) Three-phase load voltage $(V a b c)$.

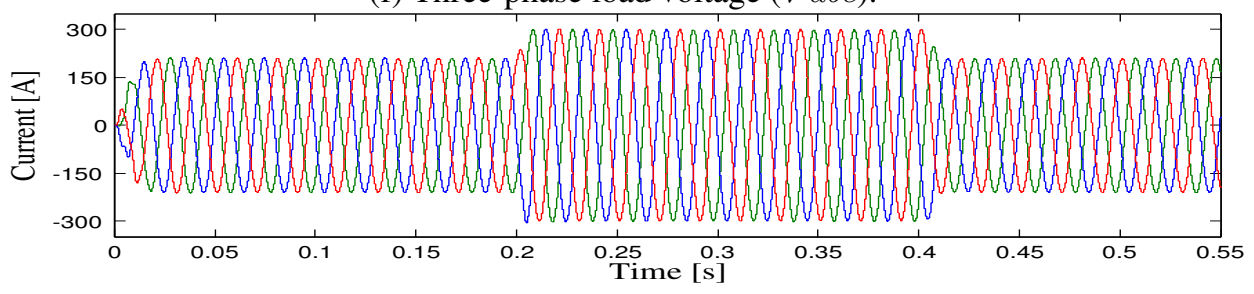

(g) Load current $(I a b c)$.

Fig. 6. Simulation results (Scenario - 2) 


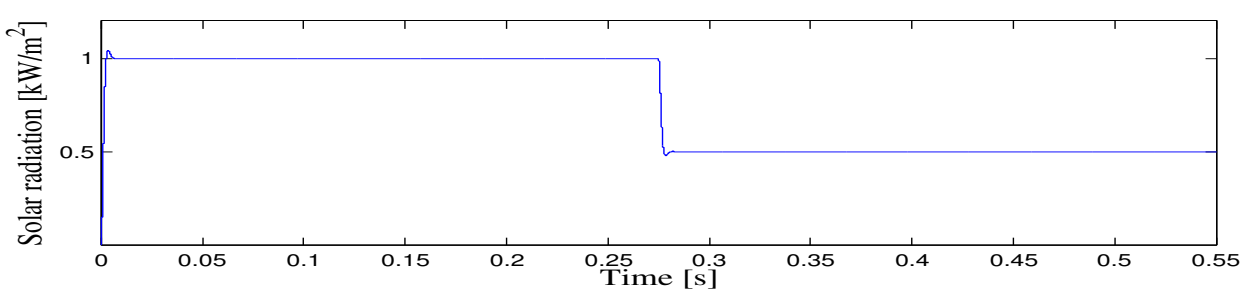

(a) Solar radiation.

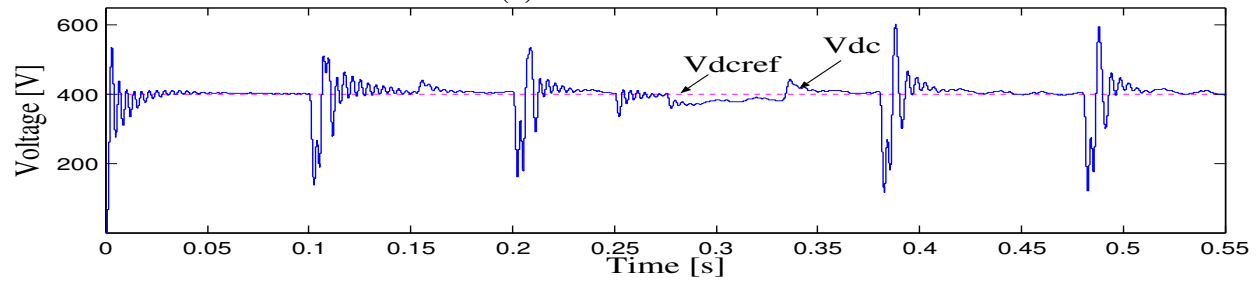

(b) Voltage on Dc-link $(V d c-l i n k)$.

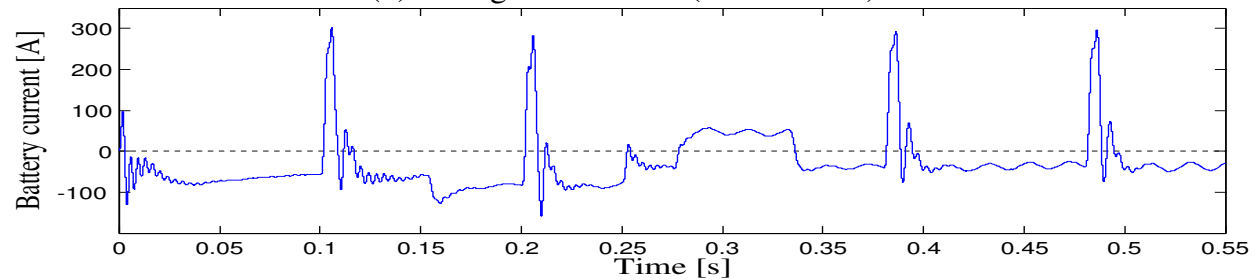

(c) Battery current $(i b)$.

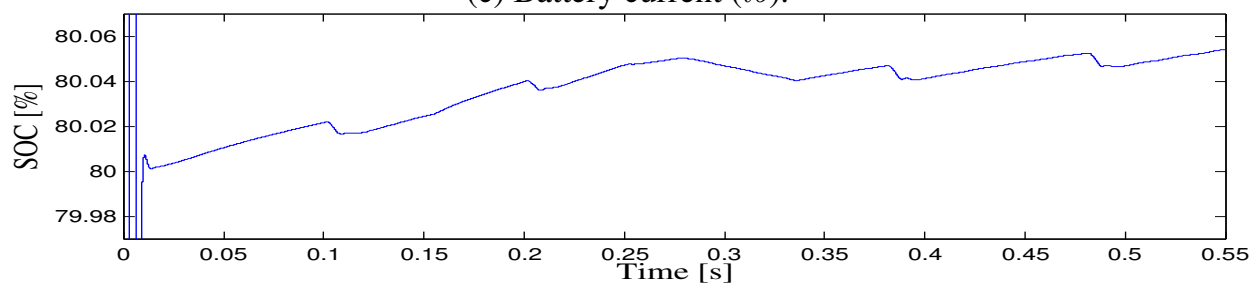

(d) State-of-Charge $(S O C)$.

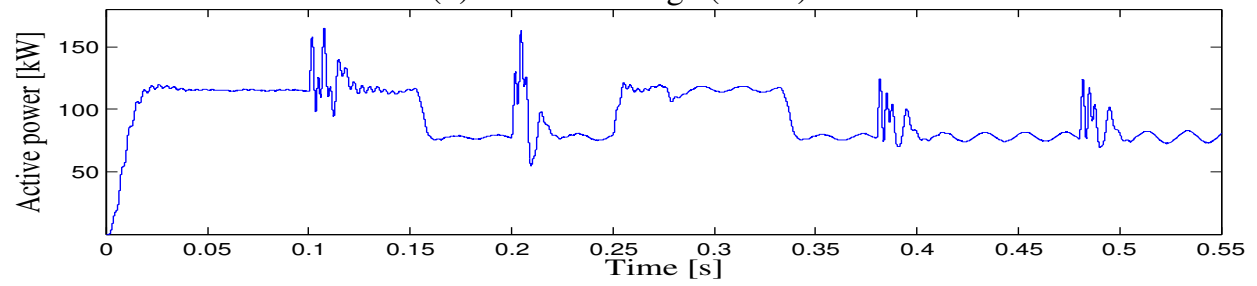

(e) Active power injected into inverter $(\mathrm{Pe})$.

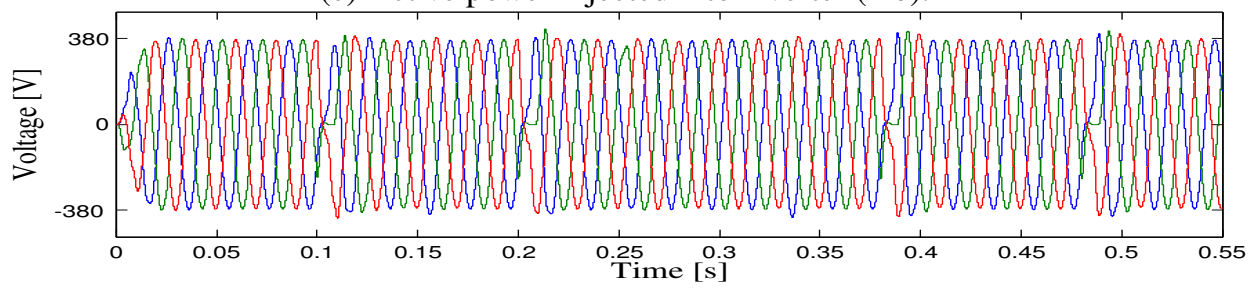

(f) Three-phase load voltage $(V a b c)$.

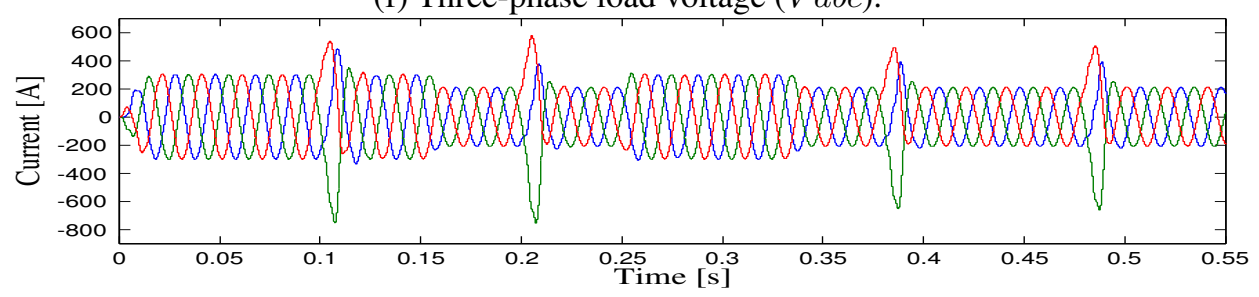

(g) Load current $(I a b c)$. 


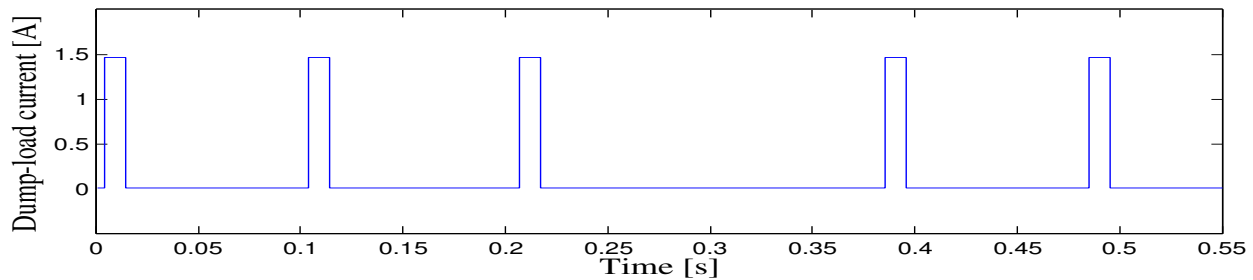

(a) Overvoltage detection on Dc-link.

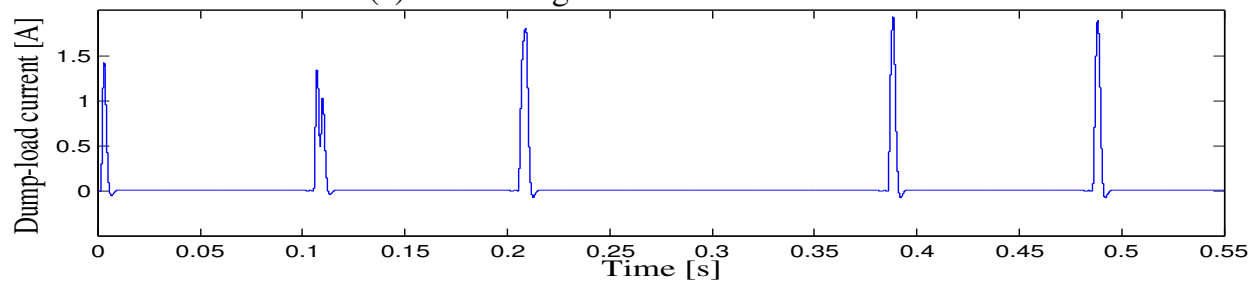

(b) Dump-load current $\left(i_{r c}\right)$.

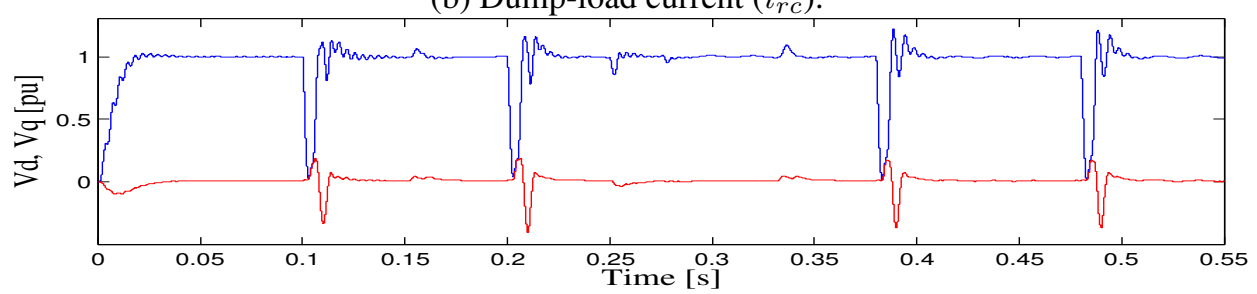

(c) Load voltage in $d q$ reference $(V d q)$.

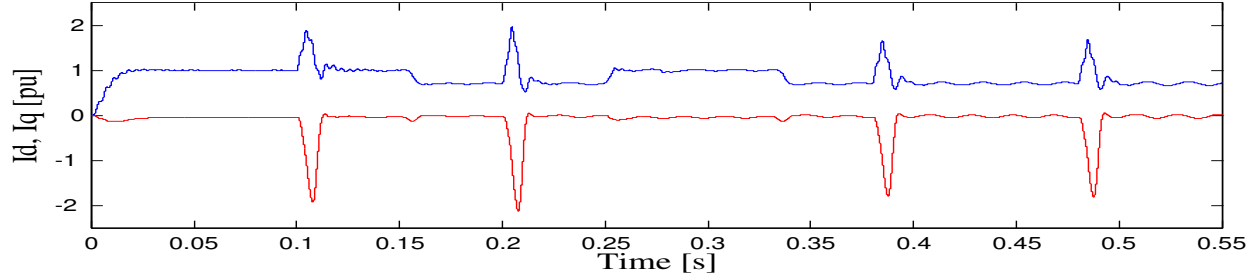

(d) Load current in $d q$ reference $(I d q)$.

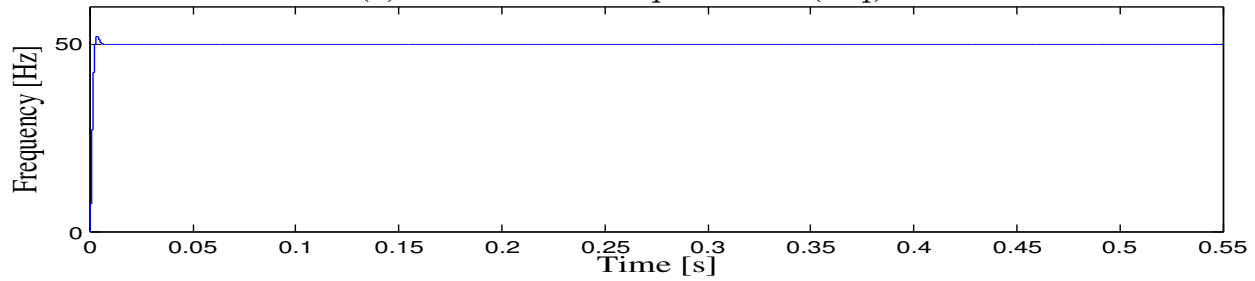

(e) Grid frequency $f$.

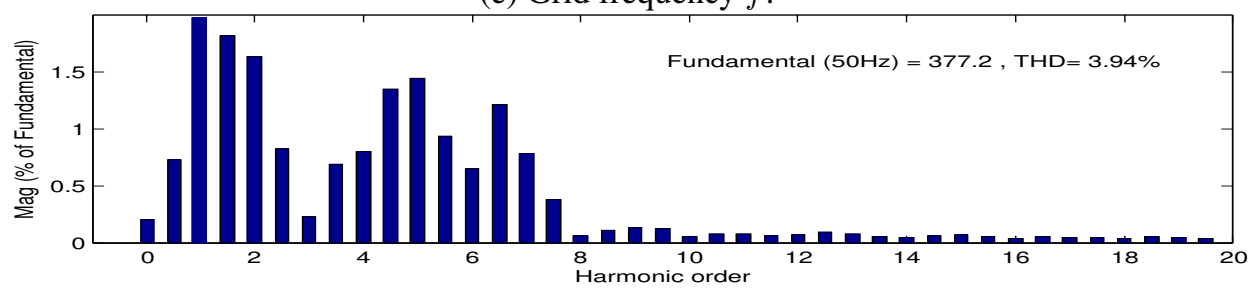

(f) Total Harmonic Distortion $(T H D)$.

Fig. 7. Simulation results (Scenario - 3) 